\title{
Challenges of informed consent during a political crisis: A case study of research with a marginalised group
}

\author{
SAPNA MISHRA, RAKHAL GAITONDE
}

\begin{abstract}
Ethical guidelines mandate that the researcher must obtain written informed consent either from the participant or from an impartial witness before commencing data collection. This case study describes some issues faced in trying to put this into practice. The research project in which these issues arose aimed to study occupational health problems and healthcare-seeking practices among workers in the unorganised e-waste sector in a south Indian city. The process of collecting written informed consent proceeded smoothly until the passage of the Citizenship Amendment Act. This made these workers extremely anxious. They were ready to participate but refused to sign any document. In these circumstances, identifying an "impartial witness" or a "study independent person", the recommended alternative to written consent by the institutional ethics committee, was impossible, given the closeknit community that was being studied and the fact that everyone was involved in one way or the other with e-waste related work.
\end{abstract}

Keywords: informed consent, impartial witness, e-waste workers

\section{Introduction}

Like other types of waste, electrical and electronic waste (ewaste) is also predominantly managed by the unorganised sector in developing countries such as India. The workforce largely comprises of marginalised groups (ethnic or religious minorities) and migrants who work under precarious conditions to make a living through collecting, sorting, and recycling waste.(1) This precarity poses a threat to workers' health, making them vulnerable to occupational injuries and work-related diseases (2). Their occupational precarity is just

Authors: Sapna Mishra (corresponding author sapnamishra2510@gmail.com), PhD Student, Achutha Menon Centre for Health Science Studies, Sree Chitra Institute for Medical Science and Technology, Thiruvananthapuram, Kerala INDIA; Rakhal Gaitonde (rakhal.gaitonde@sctimst.ac.in), Professor, Achutha Menon Centre for Health Science Studies, Sree Chitra Institute for Medical Science and Technology, Thiruvananthapuram, Kerala, INDIA.

To cite: Mishra S., Gaitonde R. Challenges of informed consent during a political crisis: A case study of research with a marginalised group. Indian J Med Ethics. 2021 Jul-Sep; 6(3) NS: 246-248 DOI: 10.20529/IJME.2020.130.

Published online first on December 19, 2020.

Manuscript Editor: Rakhi Ghoshal

(C) Indian Journal of Medical Ethics 2020 one dimension of the vulnerability of these groups who are marginalised in many ways by society; they are socially stigmatised, poorly-organised, economically-exploited, as well as politically marginalised (3).

This case presents the ethical dilemma encountered by the researcher who was studying occupational health problems and healthcare-seeking practices among workers in the unorganised e-waste sector in a south Indian city. The methodology of the research includes surveys and in-depth interviews with these workers. The research was approved by the Institutional Ethics Committee (IEC) of the institute to which the authors are affiliated.

\section{The case}

The researcher started her fieldwork in mid-November 2019. Based on prior knowledge regarding the ongoing struggles of the local community to resist re-location, and their being labelled as "pollution creators" by the media (4), the author had expected resistance from the participants, to the collection of personal data as well as to the signing of documents related to the consent process. This was because of their possible anxiety that the information gathered may be used against them in some way. As expected, and despite attempts at developing familiarity with the community, the researcher did experience resistance from the workers as they perceived her as someone representing a government department responsible for assessing the pollution in the locality. This was reflected in the way participants made emphatic statements about how their work did not cause any pollution. They also mentioned that the employers would be angry if they stopped the work even for five minutes.

Some of them who were ready to participate, refused to participate when they came to know that they had to sign a paper indicating their willingness. Despite repeated assurances for more than a week that this research would not harm them in any way, many participants did not agree to sign. The researcher then consulted senior members of the community who had facilitated her entry into the area in the first place. They suggested that a young person (25-year-old adult male) from the local community could accompany the researcher as a guide and help her in convincing workers to be part of the study. To formalise the relationship between the researcher and the guide, the researcher decided to compensate him for time spent, and this strategy worked well.

The survey was progressing as planned until the time the national government passed the Citizenship Amendment Act (CAA)* on December 11, 2019. This along with its links to 
a proposed National Register of Citizens (NRC), led to a lot of anxiety among the workers. These workers were Muslims, and the Muslim community felt the most insecure concerning CAA and NRC (5). They believed that these policies question their identity, and that the government would take everything away from them and send them to detention camps. At this point, a few workers told the researcher that they were receiving messages through social media that were exhorting them not to sign any paper given by an outsider. Though the researcher had already spent a few months with them and gained their confidence through the intervention of the seniors in the community, she again began to feel like an outsider. Moreover, for the workers, she was perceived as representing the government as she belonged to a central government institute. The trust she had gained over the past few months began to erode and the workers reverted to being sceptical about her intentions. The researcher's identity her caste, religion, and political ideology, which were never discussed before the announcement of CAA began to be probed by the participants. One of them even told her:

"We will have to leave this country as we won't be allowed to stay here. But you are lucky, you belong to their religion, you don't have to go through all these."

Though they were still ready to participate in the survey, they mentioned now that there was no question of signing any document.

The researcher reported this issue to the IEC of the institute which, in response, recommended that the researcher should proceed with the study, with the oral consent of the participants, but in the presence of a study-independent person who should witness the oral consent process and should sign to indicate the same.

\section{The dilemma}

In the situation of tension created by the announcement of the CAA where obtaining direct signed consent was no longer possible, the researcher was forced to rely on an impartial witness. As per the ICMR ethical guidelines an impartial witness, who could sign, would have to be a literate person who was not a relative of the participant and not be in any way connected to the ongoing research (6). The particular situation in which the research was conducted, especially in the context of the tension over the CAA / NRC bill, made it impossible to identify an "impartial witness".

In order to meet the requirements of the sample size for the survey, it was decided to include participants from all the ewaste handling units which meant that all those in the area who would be eligible to be witnesses were potential participants. As the data collection had already started when the CAA / NRC tensions emerged - the situation and rapport between the researcher and the community only became more tense, and the introduction of any new person at this time, as a witness, was fraught with the risk of breaking down the tenuous relationship that was being maintained.

In this case, the researcher is confronted with the following dilemmas:

- If she decided to use the same guide as an impartial witness in the informed consent process, and carried out research with the help of the guide who was a stakeholder in the research and had strong community ties, the researcher would be breaching the guidelines, as workers would participate not of their own choice but because of a subtle form of pressure induced by their familiarity with the guide. This would compromise their autonomy, one of the most important principles of ethics.

- The introduction of any third party (impartial or otherwise), in the vitiated situation created by the announcement of CAA, could have been perceived as a threat because a new person would be considered as an outsider. Secondly, no matter how trustworthy the independent witness, it could breach the anonymity of participants merely by revealing their identity, especially in these distressing and turbulent times to persons who may or may not be seen as trustworthy by them.

- Further, the introduction of any third party at this point of the political crisis would have compelled the researcher to abandon her research which would result in leaving the health problems and healthcare needs of these workers undocumented.

In this situation identifying someone who is not directly involved in the research, and is not directly related to those who are participants was a challenge.

\section{Questions raised by the case regarding fulfilment of the process of informed consent}

- To what extent does the requirement of a study. independent person/an impartial witness while getting oral consent, hold relevance in this context of a closely-knit marginalised community that perceives itself as insecure in an adverse political scenario?

- Is it even possible to have a study-independent person/impartial witness in a context where conducting the research would be nearly impossible without the involvement of a local community member who had, close community ties which would influence the autonomy of the participants?

- If so, who should be considered as a study-independent person/ an impartial witness in this context?

\section{Acknowledgement}

The authors would like to thank Professor Mala Ramanathan, Achutha Menon Centre for Health Science Studies, for her valuable inputs.

\section{Note}

* The CAA provides citizenship to the following religious groups - Hindu, Jain, Sikh, Buddhist, Parsi, and Christian religious minorities - who moved to India from Pakistan, Bangladesh and Afghanistan on or before the 31st day of December, 2014, as a result of persecution faced. However, there is no mention about the Muslim community. For further details please refer http:// egazette.nic.in/WriteReadData/2019/214646.pdf

\section{References}

1. Lundgren MK. The global impact of e-waste: addressing the challenge. Geneva: International Labour Organization; 2012 [cited 2019 Aug 28]. Available from: https://www.ilo.org/wcmsp5/groups/ public/---ed_dialogue/---sector/documents/publication/wcms_196105.pdf

2. International Labour Organization. Informal economy: a hazardous activity. Geneva: ILO; 2009 [cited 2019 Aug 28]. Available from: http- 
s://www.ilo.org/global/topics/safety-and-health-at-work/areasofwork/hazardous-work/WCMS_110305/lang--en/index.htm

3. Harriss-White B. Waste, social order, and physical disorder in smalltown India. J Dev Stud. 2020 Feb 1[cited 2020 Aug 29];56(2):239-58. Available from: https://www.tandfonline.com/doi/abs/ 10.1080/00220388.2019.1577386

4. Kumar SS. No more stinking tanneries in Bholakpur. Telangana Today 2016 December 25 [cited 2020 July 28]. Available from: https:// telanganatoday.com/stinking-tanneries-bholakpur

5. Chandrachud A. Secularism and the Citizenship Amendment Act. Rochester, NY: Social Science Research Network; 2020 Jan [cited $2020 \mathrm{Jul}$ 28]. Report No: ID 3513828. Available from: https:// papers.ssrn.com/abstract $=3513828$

6. Indian Council of Medical Research. National ethical guidelines for biomedical and health research involving human participants. New Delhi: ICMR; 2017

\title{
COMMENTARY
}

\section{Intention, perception and trust: comment on "Challenges of informed consent during a political crisis" by Mishra and Gaitonde}

\author{
SRIVATSAN R
}

\begin{abstract}
This note explores the relevance of the ethics requirement of having a "study-independent observer/impartial witness" signing off on the informed consent procedure when the community under study is unwilling to do so. It shows how the community's distrust of the researcher as an agent of a malevolent government (expressed in a refusal to sign the consent form) is reflected in the researcher's objective links to government through education and advanced academic research. The note argues that research ethics, rather than blindly following rules, means thinking about context. It reverses the question of relevance of the ethics protocol, to questioning the relevance of the research to the community. It suggests that thinking this through will clarify the position of the researcher and contribute to research ethics
\end{abstract}

Keywords: Informed consent, impartial witness, public health research ethics, Citizenship Amendment Act, National Register of Citizens.

Sapna Mishra and Rakhal Gaitonde have posed (1) an ethical challenge in the political context of their research with a marginalised community, broadly summarised below:

Author: Srivatsan R (r.srivats@gmail.com), formerly Senior Fellow, Anveshi Research Centre for Women's Studies, Hyderabad, India

To cite: Srivatsan R. Intention, perception and trust: comment on "Challenges of informed consent during a political crisis" by Mishra and Gaitonde. Indian J Med Ethics. 2021 Jul-Sep; 6(3)NS: 248-250. DOI: 10.20529/ IJME.2021.052

C Indian Journal of Medical Ethics 2021
How relevant is the research ethics requirement of a "study independent impartial observer" signing off the gathering of informed consent, when insecure Muslim participants distrust the researcher as an agent of an illintentioned government in the context of the Citizenship Amendment Act (CAA) and National Register of Citizens (NRC) of India? ${ }^{1}$

The relevant definition in the Indian Council of Medical Research (ICMR) research guidelines (2) is:

Impartial Witness: 'literate person, who is independent of the research and would not be unfairly influenced by people involved with the study, who attends the informed consent process if the participant and/or their LAR (Legally Acceptable Representative) cannot read and understand the informed consent form and any other written information supplied to the participant. (emphasis mine)' (2: p 155)

\section{The participants' viewpoint}

We approach this question of relevance of having a studyindependent, impartial witness from a different perspective: ie., aligned to the targeted community which sees the researcher as a representative of a malevolent State. Why should the community trust a witness chosen by an untrusted researcher? From this perspective, the authors' question of relevance posed in relation to the impartial witness translates to the more fundamental one: Why is the researcher perceived with suspicion by the community, and further, what is the relevance of her work to them?

For the community members, the researcher working in a government institution is a representative of the State. Their own relationship to the State is one of fear, avoidance and 